\title{
PERAMALAN JUMLAH KUNJUNGAN WISATAWAN MANCANEGARA DI KEPULAUAN RIAU DENGAN MENGGUNAKAN MODEL FUNGSI TRANSFER
}

\author{
Tamura Rolasnirohatta $\mathrm{S}^{1}$, Rukun Santoso ${ }^{2}$, Alan Prahutama ${ }^{3}$ \\ 1,2,3 Departemen Statistika, Fakultas Sains dan Matematika, Universitas Diponegoro \\ e-mail : tamurasiahaan7@gmail.com
}

\begin{abstract}
Transfer function models is a data analysis model that combines time series and causal approach, in another words, transfer function models is a method that ilus trates that the predicted value in teh future is affected by the past value time series and based on one or more related time series. In this research, an analysis of the number of tourist arrival and rainfall in several regions in Kepulau an Riau fromJanuary 2013 untilDecember 2017 was aimed at obtaining a transfer function model and forecasting the number of tourist arrival in several regions of the Kepulauan Riau for next periods. Based on the result of the analysis, rainfall in Tanjung Pinang does not affect the visit of tourist with the values of MAPE is 13,63494\%. Rainfall in Batam also does not affect the visit of tourist with the values of MAPE is 7,977151\%. While in Tanjung Balai Karimun, tourist arrivals was affected by rainfall with the values of MAPE is $10,32777 \%$.
\end{abstract}

Keywords: Rainfall, Transfer Function Model, Tourist.

\section{PENDAHULUAN}

Pariwisata merupakan salah satu jenis industri yang mampu mempercepat pertumbuhan ekonomi dan penyediaan lapangan kerja, peningkatan penghasilan, standar hidup serta menstimuli sektor-sektor produktif lainnya. Oleh karena itu, pemerintah daerah harus mengupayakan pengembangan potensi objek-objek wisata yang ada sehingga dapat menarik wisatawan untuk berkunjung ke objek wisata tersebut.

Kepulauan Riau merupakan salah satu provinsi di Indonesia yang berdekatan dengan negara Singapura dan Malaysia sehingga Kepulauan Riau menjadi salah satu destinasi pariwisata favorit bagi wisatawan mancanegara terutama wisatawan berkebangsaan Singapura dan Malaysia. Kunjungan wisatawan mancanegara ternyata dipengaruhi beberapa factor, salah satunya adalah faktor curah hujan.

Model fungsi transfer merupakan metode yang menggambarkan bahwa nilai prediksi masa depan dari suatu deret waktu (disebut deret output) didasarkan pada nilai-nilai masa lalu dari deret waktu itu sendiri dan didasarkan pada satu atau lebih deret waktu yang berhubungan (disebut deret input). Berdasarkan uraian yang telah dijelaskan, penulis tertarik untuk membahas secara lebih lanjut mengenai model fungsi transfer dengan membuat algoritma dan program dalam program $\mathrm{R}$ serta menerapkan hasilnya pada data jumlah kunjungan wisatawan mancanegara dan curah hujan di beberapa daerah di Kepulauan Riau.

\section{TINJAUAN PUSTAKA}

\subsection{Pe ramalan}

Peramalan merupakan suatu kegiatan memprediksi yang akan terjadi di masa yang akan datang. Menurut Soejoeti (1987), peramalan adalah salah satu unsur yang sangat penting dalam pengambilan keputusan, sebab efektif tidaknya suatu keputusan umumnya tergantung pada beberapa faktor yang tidak dapat dilihat pada waktu keputusan itu diambil.

\subsection{Konsep Dasar Time Series}

Salah satu ciri dalam pembentukan model time series adalah mengasumsikan data dalam keadaan stasioner, baik stasioner dalam mean maupun stasioner dalam varian. Uji stasioner data dalam mean dapat menggunakan uji Dickey Fuller. Pada data yang tidak 
stasioner dalam mean perlu dilakukan pembedaan (differencing). Secara umum, differencing orde ke-d ditulis sebagai berikut (Wei, 2006):

$\Delta^{d} Z_{t}=(1-B)^{d} Z_{t}$

Uji stasioner data dalam varian dapat menggunakan transformasi Box-Cox yang dirumuskan sebagai berikut (Wei, 2006):

$\mathrm{T}\left(Z_{t}\right)= \begin{cases}\frac{z_{t}^{\lambda}-1}{\lambda} & \lambda \neq 0 \\ \lim \frac{z_{t}^{\lambda}-1}{\lambda}=\ln \left(Z_{t}\right) & \lambda=0\end{cases}$

Suatu proses $\left(Z_{t}\right)$ yang stasioner akan terdapat nilai rata-rata dan varian yang konstan, yaitu mean $E\left(Z_{t}\right)=\mu$, dan varian $\operatorname{var}\left(Z_{t}\right)=E\left(Z_{t}-\mu\right)^{2}=\sigma_{z}^{2}$ dan kovarian $\operatorname{Cov}\left(Z_{t}, Z_{t+k}\right)$. Kovarian antara $Z_{t}$ dan $Z_{t+k}$ adalah sebagai berikut :

$\gamma_{k}=\operatorname{cov}\left(Z_{t}, Z_{t+k}\right)=E\left(Z_{t}-\mu\right)\left(\left(Z_{t+k}-\mu\right)\right.$

Sedangkan autokorelasi antara $Z_{t}$ dan $Z_{t+k}$ didefinisikan sebagai:

$\rho_{k}=\frac{\operatorname{Cov}\left(Z_{t}, Z_{t+k}\right)}{\sqrt{\operatorname{var}\left(Z_{t}\right)} \sqrt{\operatorname{var}\left(Z_{t+k}\right)}}=\frac{\gamma_{k}}{\gamma_{0}}$

Selanjutnya, $\gamma_{k}$ dinamakan fungsi autokovariansi dan $\rho_{k}$ dinamakan fungsi autokorelasi (ACF). Ukuran korelasi yang lain pada analisis time series adalah fungsi autokorelasi parsial (PACF). Nilai PACF dinyatakan sebagai berikut (Soejoeti, 1987):

$\emptyset_{k k}=\frac{P_{k}^{*}}{P_{k}}$

\subsection{Model Time Series ARIMA} berikut:

Menurut Wei (2006), beberapa model time series dapat dikelompokkan sebagai

1. Model Autoregressive orde $\mathrm{p}$ atau AR $(p)$

Bentuk umum dari model AR orde $\mathrm{p}$ adalah sebagai berikut:

$Z_{t}=\phi_{1} Z_{t-1}+\phi_{2} Z_{t-2}+\cdots+\phi_{p} Z_{t-p}+a_{t}$

2. Model Moving Average (MA)

Bentuk umum dari model MA orde $\mathrm{q}$ adalah sebagai berikut:

$Z_{t}=a_{t}-\theta_{1} a_{t-1}-\cdots-\theta_{q} a_{t-q}$

3. Model Autoregressive Moving Average atau ARMA $(p, q)$

Bentuk umum dari model ARMA $(\mathrm{p}, \mathrm{q})$ adalah sebagai berikut:

$Z_{t}=\phi_{1} Z_{t-1}+\cdots+\phi_{p} Z_{t-p}+a_{t}-\theta_{1} a_{t-1}-\cdots-\theta_{q} a_{t-q}$

4. Model Autoregressive Integrated Moving Average atau ARMA $(p, d, q)$

Bentuk umum dari model ARIMA $(\mathrm{p}, \mathrm{d}, \mathrm{q})$ adalah sebagai berikut:

$\phi_{p}(B)(1-B)^{d} Z_{t}=\theta_{q} a_{t}$

Terdapat empat tahapan dalam pembentukan model ARIMA yaitu identifikasi model, estimasi parameter, uji signifikansi parameter dan uji diagnostik model yang terdiri dari uji Ljung-Box dan uji normalitas. Model terbaik dipilih berdasarkan nilai AIC terkecil (Wei, 2006).

\subsection{Pemodelan Fungsi Transfer}

Menurut Makridakis et al. (1988), model fungsi transfer adalah suatu model di mana terdapat deret berkala output, disebut Yt, yang diperkirakan akan dipengaruhi oleh deret berkala input, disebut $\mathrm{Xt}$, dan input-input lain yang digabungkan dalam suatu kelompok yang disebut gangguan (noise). Model umum dari fungsi transfer adalah:

$y_{t}=\frac{\omega_{s}(B)}{\delta_{r}(B)} x_{t}+\frac{\theta(B)}{\emptyset(B)} a_{t}$ 
Tahap-tahap dalam pembentukan model fungsi transfer adalah:

1. Persiapkan deret input dan deret output.

2. Prewhitening deret input dan prewhitening deret output.

3. Perhitungan fungsi korelasi silang.

4. Penetapan $b, s, r$ untuk model fungsi transfer.

5. Penetapan model fungsi transfer.

6. Estimasi parameter model fungsi transfer.

7. Uji diagnostik model fungsi transfer.

8. Pemilihan model fungsi transfer terbaik berdasarkan nilai AIC terkecil, lalu melakukan peramalan.

\section{METODE PENELITIAN}

Data yang digunakan merupakan data data sekunder yang diperoleh dari Badan Pusat Statistik (BPS) Provinsi Kepulauan Riau tentang data bulanan kunjungan wisatawan mancanegara (jiwa) dan data sekunder yang diperoleh dari www.bmkg.go.id tentang data bulanan curah hujan (mm) di 3 daerah di Kepulauan Riau yaitu kota Batam, Tanjung Pinang dan Tanjung Balai Karimun periode Januari 2013 sampai Desember 2017. Langkah-langkah analisis dapat digambarkan melalui diagram alir sebagai berikut:

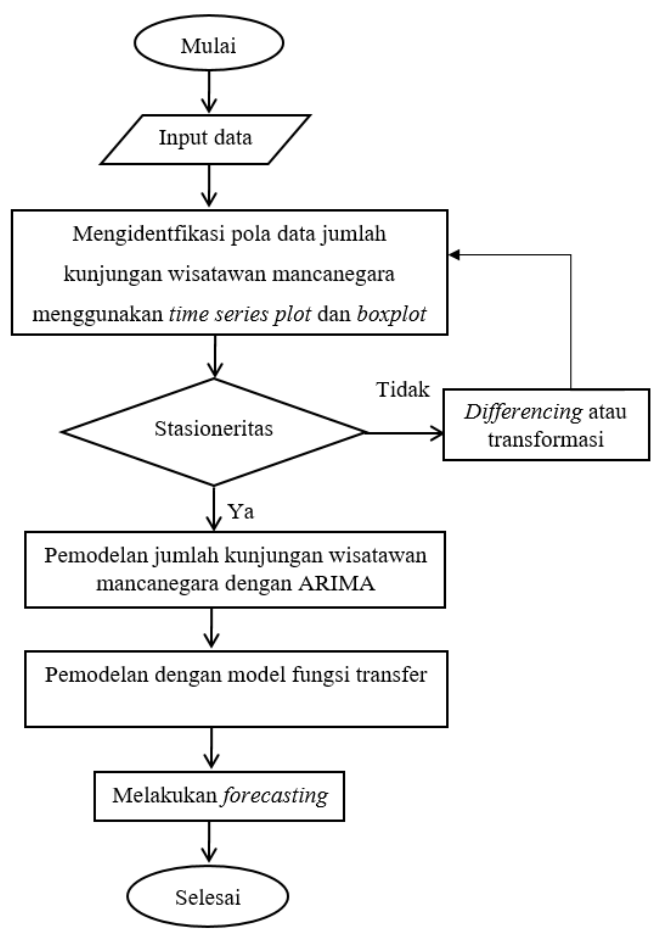

Gambar 1 Diagram Alir Tahapan Metode Model Fungsi Transfer

\section{HASIL DAN PEMBAHASAN}

\subsection{Pemodelan ARIMA Wisatawan Mancanegara}

\section{a. Wisatawan Mancanegara di Tanjung Pinang}

Setelah dilakukan uji stasioneritas dalam mean dan varian, lalu mengidentifikasi model, selanjutnya melakukan uji signifikansi parameter, uji independensi residual dan uji normalitas residual model, maka model ARIMA $(0,1,1)$ dipilih sebagai model terbaik untuk wisatawan mancanegara di Tanjung Pinang dengan nilai AIC sebesar 1039,98. Model ARIMA $(0,1,1)$ adalah sebagai berikut:

$$
Z_{t}=0,2941 Z_{t-1}+0,1245 Z_{t-2}+0,5814 Z_{t-3}+a_{t}
$$




\section{b. Pemodelan ARIMA Wisatawan Mancanegara di Batam}

Setelah dilakukan uji stasioneritas dalam mean dan varian, lalu mengidentifikasi model, selanjutnya melakukan uji signifikansi parameter, uji independensi residual dan uji normalitas residual model, maka model ARIMA $(2,1,0)$ dipilih sebagai model terbaik untuk wisatawan mancanegara di Batam dengan nilai AIC sebesar 1299,88. Model ARIMA $(2,1,0)$ adalah sebagai berikut:

$$
Z_{t}=0,3252 Z_{t-1}+0,21783 Z_{t-2}+0,45697 Z_{t-3}+a_{\mathrm{t}}
$$

\section{c. Pemodelan ARIMA Wisatawan Mancanegara di Tanjung Balai Karimun}

Setelah dilakukan uji stasioneritas dalam mean dan varian, lalu mengidentifikasi model, selanjutnya melakukan uji signifikansi parameter, uji independensi residual dan uji normalitas residual model, maka model ARIMA $(2,1,0)$ dipilih sebagai model terbaik untuk wisatawan mancanegara di Tanjung Balai Karimun dengan nilai AIC sebesar 995,97. Model ARIMA $(2,1,0)$ adalah sebagai berikut:

$$
Z_{t}=0,26307 Z_{t-1}+0,39862 Z_{t-2}+0,22831 Z_{t-3}+a_{t}
$$

\subsection{Model Fungsi Transfer}

\section{Model Fungsi Transfer Tanjung Pinang}

\section{a. Pemodelan ARIMA Curah Hujan di Tanjung Pinang}

Setelah dilakukan uji stasioneritas dalam mean dan varian, lalu mengidentifikasi model, selanjutnya melakukan uji signifikansi parameter, uji independensi residual dan uji normalitas residual model, maka model ARIMA $(0,1,1)$ dipilih sebagai model terbaik untuk curah hujan di Tanjung Pinang dengan nilai AIC sebesar 763,36. Model ARIMA $(0,1,1)$ adalah sebagai berikut:

$$
X_{1 t}=X_{1 t-1}+a_{1 t}+0,7027 a_{1 t-1}
$$

\section{b. Pemodelan Fungsi Transfer Tanjung Pinang}

$\checkmark$ Prewhitening deret input

Model prewhitening deret input curah hujan di Tanjung Pinang adalah sebagai berikut:

$$
\alpha_{1, t}=X_{1, t}-X_{1, t-1}-0,7027 \alpha_{1, t-1}
$$

$\checkmark$ Prewhitening deret output

Model prewhitening deretoutput dengan variabel inputcurah hujan di Tanjung Pinang adalah sebagai berikut:

$$
\beta_{1, t}=Y_{1, t}-Y_{1, t-1}-0,7027 \beta_{1, t-1}
$$

\section{Pembentukan fungsi korelasi silang (Cross Correlation Function)}

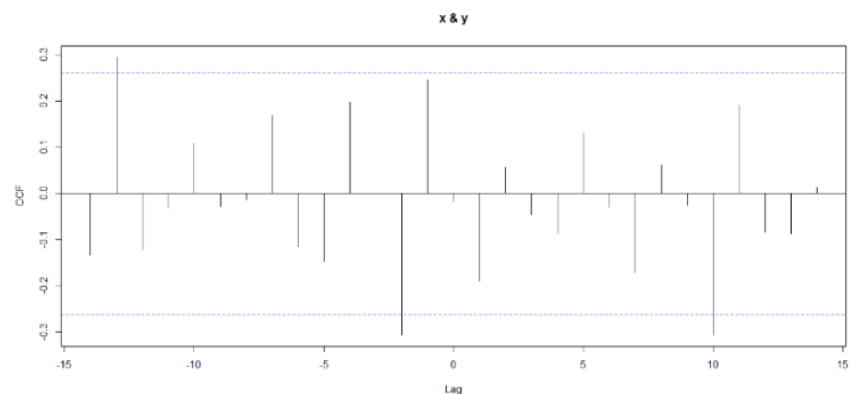

Gambar 2 Plot $C C F$ Jumlah Wisatawan Mancanegara dan Curah Hujan di Tanjung Pinang

Penetapan orde $b, s, r$ dan penaksiran awal deret gangguan 
Berdasarkan Gambar 2, maka diperoleh nilai $b=1, r=2$ dan $s=1$. Model fungsi transfer sementara adalah sebagai berikut:

$$
y_{1, t}=\frac{\left(\omega_{0}-\omega_{1} B\right)}{\left(1-\delta_{1} B-\delta_{2} B^{2}\right)} x_{1, t-1}+\text { noise }
$$

Tahapan selanjutnya adalah menghitung taksiran awal komponen noise dari model fungsi transfer. Setelah dilakukan uji stasioneritas dalam mean dan varian, lalu mengidentifikasi model, selanjutnya melakukan uji signifikansi parameter, uji independensi residual dan uji normalitas residual model, maka model ARIMA $(2,1,0)$ dipilih sebagai model terbaik untuk model deret noise di Tanjung Pinang dengan nilai AIC sebesar 992,49. Maka diperoleh model fungsi transfer untuk Tanjung Pinang adalah sebagai berikut:

$$
Y_{1, t}=Y_{1, t-1}+\frac{a_{1, t}}{\left(1+0,6702 \mathrm{~B}+0,4131 B^{2}\right)}
$$

Peramalan

Berdasarkan model fungsi transfer, diperoleh hasil peramalan jumlah kunjungan wisatawan mancanegara sebagai berikut:

Tabel 1 Hasil Ramalan Jumlah Kunjungan Wisatawan

Mancanegara di Tanjung Pinang
Periode
Peramalan

Januari 2018

11684

Februari 2018

11333

Maret 2018

13147

April 2018

12071

Mei 2018

11776

Juni 2018

12610

Juli 2018

12193

Agustus 2018

12002

September 2018

12379

Oktober 2018

12224

November 2018

12115

Desember 2018

12282

\section{Model Fungsi Transfer Batam}

\section{a. Pemodelan ARIMA Curah Hujan di Batam}

Setelah dilakukan uji stasioneritas dalam mean dan varian, lalu mengidentifikas i model, selanjutnya melakukan uji signifikansi parameter, uji independensi residual dan uji normalitas residual model, maka model ARIMA $(0,1,1)$ dipilih sebagai model terbaik 
untuk curah hujan di Batam dengan nilai AIC sebesar 731,45. Model ARIMA (0,1,1) adalah sebagai berikut:

$$
X_{2, t}=X_{2, t-1}+a_{2, t}+0,9133 a_{2, t-1}
$$

b. Pemodelan Fungsi Transfer Batam

$\checkmark$ Prewhitening deret input

Model prewhitening deret input curah hujan di Batam adalah sebagai berikut:

$$
\alpha_{2, t}=X_{2, t}-X_{2, t-1}-0,9133 \alpha_{2, t-1}
$$

$\checkmark$ Prewhitening deret output

Model prewhitening deret output dengan variabel input curah hujan di Batam adalah sebagai berikut:

$$
\beta_{2, t}=Y_{2, t}-Y_{2, t-1}-0,9133 \beta_{2, t-1}
$$

$\checkmark$ Pembentukan fungsi korelasi silang (Cross Correlation Function)

$\times 8 y$

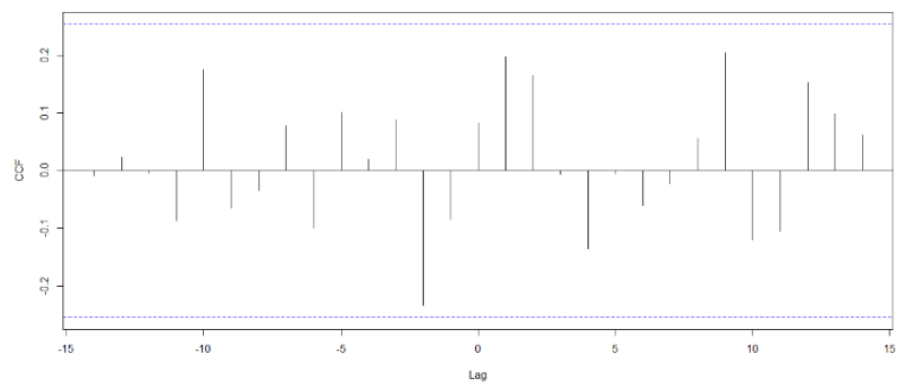

Gambar 3 Plot CCF Jumlah Wisatawan Mancanegara dan Curah Hujan di Batam

Penetapan orde $\mathrm{b}, \mathrm{s}, \mathrm{r}$ dan penaksiran awal deret gangguan

Berdasarkan Gambar 3, maka diperoleh nilai $\mathrm{b}=1, \mathrm{r}=2$ dan $\mathrm{s}=1$. Model fungsi transfer sementara adalah sebagai berikut:

$$
y_{2, t}=\frac{\left(\omega_{0}-\omega_{1} B\right)}{\left(1-\delta_{1} B-\delta_{2} B^{2}\right)} x_{2, t-1}+\text { noise }
$$

Tahapan selanjutnya adalah menghitung taksiran awal komponen noise dari model fungsi transfer. Setelah dilakukan uji stasioneritas dalam mean dan varian, lalu mengidentifikasi model, selanjutnya melakukan uji signifikansi parameter, uji independensi residual dan uji normalitas residual model, maka model ARIMA $(0,1,1)$ dipilih sebagai model terbaik untuk model deret noise di Batam dengan nilai AIC sebesar 1836,64. Maka diperoleh model fungsi transfer untuk Batam adalah sebagai berikut:

$$
Y_{2, t}=Y_{2, t-1}+a_{2, t}+a_{2, t-1}
$$

$\checkmark$ Peramalan

Berdasarkan model fungsi transfer, diperoleh hasil peramalan jumlah kunjungan wisatawan mancanegara di Batam sebagai berikut:

Tabel 2 Hasil Ramalan Jumlah Kunjungan

Wisatawan Mancanegara di Batam

Periode Peramalan

Januari $2018 \quad 127384$


Februari 2018

129595

Maret 2018

139715

April 2018

131876

Mei 2018

Juni 2018

Juli 2018

Agustus 2018

September 2018

Oktober 2018

November 2018

Desember 2018
132541

135674

133256

133456

134426

133680

133740

134041

\section{Model Fungsi Transfer Tanjung Balai Karimun}

a. Pemodelan ARIMA Curah Hujan di Tanjung Balai Karimun

Setelah dilakukan uji stasioneritas dalam mean dan varian, lalu mengidentifikasi model, selanjutnya melakukan uji signifikansi parameter, uji independensi residual dan uji normalitas residual model, maka model ARIMA $(4,1,0)$ dipilih sebagai model terbaik untuk curah hujan di Tanjung Balai Karimun dengan nilai AIC sebesar 697,41. Model ARIMA $(4,1,0)$ adalah sebagai berikut:

$$
\begin{gathered}
X_{3, t}=0,7235 X_{3, t-1}-0,0634 X_{3, t-2}+0,02454 X_{3, t-3}-0,0044 X_{3, t-4} \\
+0,3198 X_{3, t-5}+a_{3, t}
\end{gathered}
$$

b. Pemodelan Fungsi Transfer Tanjung Balai Karimun

$\checkmark$ Prewhitening deret input

Model prewhitening deret input curah hujan di Tanjung Balai Karimun adalah sebagai berikut:

$$
\begin{aligned}
\alpha_{3, t}= & X_{3, t}-0,7235 X_{3, t-1}+0,0634 X_{3, t-2}-0,02454 X_{3, t-3}+0,0044 X_{3, t-4}- \\
& 0,3198 X_{3, t-5}
\end{aligned}
$$

$\checkmark$ Prewhitening deret output

Model prewhitening deret output dengan variabel input curah hujan di Tanjung Balai

Karimun adalah sebagai berikut:

$$
\begin{aligned}
\beta_{3, t}= & Y_{3, t}-0,7235 Y_{3, t-1}+0,0634 Y_{3, t-2}-0,02454 Y_{3, t-3}+0,0044 Y_{3, t-4}- \\
& 0,3198 Y_{3, t-5}
\end{aligned}
$$

$\checkmark$ Pembentukan fungsi korelasi silang (Cross Correlation Function) 


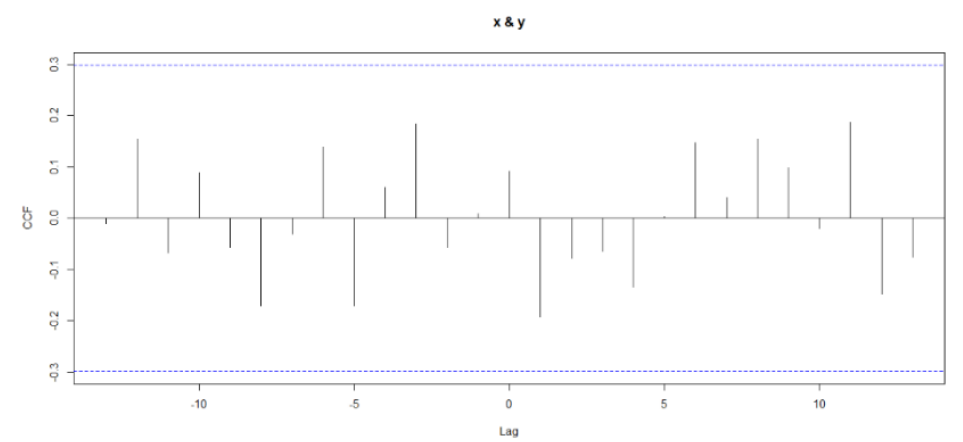

Gambar 4 Plot CCF Jumlah Wisatawan Mancanegara dan Curah Hujan di Tanjung Balai Karimun

Penetapan orde $b, s, r$ dan penaksiran awal deret gangguan

Berdasarkan Gambar 4, maka diperoleh nilai $\mathrm{b}=1, \mathrm{r}=0$ dan $\mathrm{s}=1$. Model fungsi transfer sementara adalah sebagai berikut:

$$
y_{3, t}=\left(\omega_{0}-\omega_{1} B\right) x_{3, t-1}+\text { noise }
$$

Tahapan selanjutnya adalah menghitung taksiran awal komponen noise dari model fungsi transfer. Setelah dilakukan uji stasioneritas dalam mean dan varian, lalu mengidentifikasi model, selanjutnya melakukan uji signifikansi parameter, uji independensi residual dan uji normalitas residual model, maka model ARIMA $(0,1,1)$ dipilih sebagai model terbaik untuk model deret noise di Tanjung Balai Karimun dengan nilai AIC sebesar 938,3. Maka diperoleh model fungsi transfer untuk Tanjung Balai Karimun adalah sebagai berikut:

$$
Y_{3, t}=Y_{3, t-1}+\omega_{0} x_{3, t-1}-\omega_{1} x_{3, t-2}+a_{3, t}+(0,6974) a_{3, t-1}
$$

\section{Peramalan}

Berdasarkan model fungsi transfer, diperoleh hasil peramalan jumlah kunjungan wisatawan mancanegara di Tanjung Balai Karimun sebagai berikut:

Tabel 3 Hasil Ramalan Jumlah Kunjungan Wisatawan

Mancanegara di Tanjung Balai Karimun

Periode

Januari 2018

Februari 2018

Maret 2018

April 2018

Mei 2018

Juni 2018

Juli 2018

Agustus 2018

\section{Peramalan}

\section{4}

11333

13147

12071

11776

12610

12193

12002 
September 2018

Oktober 2018

November 2018

Desember 2018
12379

12224

12115

12282

\section{KESIMPULAN}

Berdasarkan hasil dan pembahasan yang telah diperoleh, maka dapat diambil kesimpulan bahwa:

1. Model peramalan jumlah kunjungan wisatawan mancanegara di Tanjung Pinang dengan menggunakan model fungsi transfer dengan variabel input curah hujan adalah sebagai berikut:

$$
Y_{1, t}=Y_{1, t-1}+\frac{a_{1, t}}{\left(1+0.6702 \mathrm{~B}+0.4131 B^{2}\right)}
$$

2. Hasil peramalan jumlah kunjungan wisatawan mancanegara di Tanjung Pinang dengan menggunakan model fungsi transfer dengan variabel input curah hujan periode Januari 2018 hingga Desember 2018 dapat dikatakan baik karena memiliki nilai MAPE sebesar $13,63494 \%$

3. Model peramalan jumlah kunjungan wisatawan mancanegara di Batam dengan menggunakan model fungsi transfer dengan variabel input curah hujan adalah sebagai berikut:

$$
Y_{2, t}=Y_{2, t-1}+a_{2, t}+a_{2, t-1}
$$

4. Hasil peramalan jumlah kunjungan wisatawan mancanegara di Batam dengan menggunakan model fungsi transfer dengan variabel input curah hujan periode Januari 2018-Desember 2018 dapat dikatakan sangat baik karena memiliki nilai MAPE sebesar $7,977151 \%$.

5. Model peramalan jumlah kunjungan wisatawan mancanegara di Tanjung Balai Karimun dengan menggunakan model fungs transfer dengan variabel input curah hujan adalah sebagai berikut:

$$
Y_{3, t}=Y_{3, t-1}+\omega_{0} x_{3, t-1}-\omega_{1} x_{3, t-2}+a_{3, t}+(0,6974) a_{3, t-1}
$$

6. Hasil peramalan jumlah kunjungan wisatawan mancanegara di Tanjung Balai Karimun dengan menggunakan model fungsi transfer dengan variabel input curah hujan periode Januari 2018-Desember 2018 dapat dikatakan baik karena memiliki nilai MAPE sebesar $10,32777 \%$.

\section{DAFTAR PUSTAKA}

BPS. (2016). Kota Batam Dalam Angka. Batam.

Gujarati, D. 2004. Basic Econometric, Fourth Edition. New York: The McGraw Hill.

Indra, Mara, M.N., Martha,S. 2015. Peramalan Curah Hujan di Kabupaten Kubu Raya dengan Menggunakan Model Fungs Transfer Multivariat. Bimaster Vol. 04. No.3

Makridakis, S., Wheeleright, S. C., McGee, V. E. 1999. Metode dan Aplikasi Peramalan. Edisi kedua. Jakarta : Bina Aksara.

Megawati, F. (2015). Peramalan Tinggi Gelombang Berdasarkan Kecepatan Angin di Perairan Pesisir Semarang Menggunakan Model Fungsi Transfer. Jurnal Gaussian Vol. 4. No.4. 
Rosadi, D. 2012. Ekonometrika \& Analisis Time series Terapan dengan Eviews (Aplikasi untuk Bidang Ekonom, bisnis dan keuangan). Andi : Yogyakarta.

Siswanti,K.Y. (2011). Model Fungsi Transfer Multivariat dan Aplikasinya untuk Meramalkan Curah Hujan di Kota Yogyakarta. Universitas Negeri Yogyakarta, Yogyakarta.

Soejoeti, Z. 1987. Analisis Time Series. Jakarta : Karunika.

Wei, W.W.S. 2006. Time Series Analysis Univariate and Multivariate Methods Second Edition. New York: Pearson Inc. 